MaPan : Jurnal Matematika dan Pembelajaran

p-ISSN: 2354-6883 ; e-ISSN: 2581-172X

Volume 7, No 2, December 2019 (307-327)

DOI: https://doi.org/10.24252/mapan.2019v7n2a10

\title{
ETNOMATEMATIKA: MAKANAN TRADISIONAL BUGIS SEBAGAI SUMBER BELAJAR MATEMATIKA
}

\author{
Hikmawati Pathuddin'), Sitti Raehana2) \\ 1 UIN Alauddin Makassar, 2SMPIT Al-Fityan School \\ 1Jl. H. M. Yasin Limpo, Romangpolong, Kab. Gowa, \\ 2Jl. Pallantikan 1/Belibis, Kec. Somba Opu, Gowa \\ E-mail: hikma.pathuddin97@gmail.com ${ }^{1}$, raehanazakaria@ymail.com $^{2)}$
}

Submitted: 19-08-2019, Revised: 27-11-2019, Accepted: 14-12-2019

\begin{abstract}
Abstrak:
Penelitian ini bertujuan untuk menggambarkan hubungan antara matematika dan budaya, khususnya pada kebudayaan masyarakat Bugis. Fokus penelitian ini adalah eksplorasi etnomatematika pada makanan tradisional Bugis yang dapat dimanfaatkan sebagai sumber belajar matematika. Penelitian ini merupakan penelitian kualitatif dengan pendekatan etnografi. Instrumen yang digunakan dalam penelitian ini adalah human instrument, di mana peneliti berhubungan langsung dengan penelitian dan berperan sebagai pengumpul data. Teknik pengumpulan data dilakukan melalui observasi, wawancara, dan dokumentasi. Berdasarkan hasil pengumpulan data penelitian diperoleh beberapa makanan tradisional Bugis, yaitu barongko, onde-onde, doko-doko, paso, tumpi-tumpi, jompo-jompo, burasa', dan putu coppa. Hasil penelitian ini menunjukkan bahwa makanan tradisional Bugis tersebut mengandung konsep matematika yaitu geometri khususnya bangun datar dan bangun ruang. Tumpi-tumpi, jompo-jompo, dan burasa' mengandung konsep bangun datar, sedangkan barongko, onde-onde, doko-doko, paso, dan putu coppa mengandung konsep bangun ruang. Makanan tradisional Bugis tersebut dapat digunakan sebagai sumber belajar matematika di sekolah khususnya sekolah dasar dan sekolah menengah. Dengan demikian, pembelajaran matematika akan lebih bermakna karena sumber belajarnya berasal dari lingkungan budaya mereka sendiri.
\end{abstract}

Kata Kunci: Etnomatematika, Geometri, Makanan Tradisional Bugis

\section{ETHNOMATHEMATICS: BUGINESE TRADITIONAL FOOD AS MATHEMATICS LEARNING RESOURCES}

\begin{abstract}
:
This research aimed to describe the correlation between mathematics and culture, especially in Buginese society. This research was focused on ethnomathematics exploration of Buginese Traditional Food that could be used as mathematics learning resource. This research was a qualitative research with ethnography approach. The research instruments were the researcher who related directly to research and acts as the data collector, observation sheet, and interview. Data collection procedures were carried out through observation, interview, and documentation. Based on data collection, the findings showed that several Buginese traditional foods, such as barongko, onde-onde, doko-doko, paso, tumpi-tumpi, jompo-jompo, burasa', and putu coppa had mathematics concept of geometry especially plane figure and solid figure.
\end{abstract}

Copyright ( 2019, MaPan : Jurnal Matematika dan Pembelajaran 
Tumpi-Tumpi, Jompo-Jompo, and Burasa have plane figure concept, while barongko, ondeonde, doko-doko, paso, and putu coppa have solid figure concepts. Those traditional foods could be used as mathematics learning resource for students at elementary or secondary school. Therefore, learning mathematics would be more meaningful because the learning resources base on the students' cultural environment.

Keywords: Ethnomathematics, Geometry, Buginese Traditional Food

How to Cite: Pathuddin, H., \& Raehana, S. (2019). Etnomatematika: Makanan tradisional bugis sebagai sumber belajar. MaPan: Jurnal Matematika dan Pembelajaran, 7(2), 307-327.

\section{PENDAHULUAN}

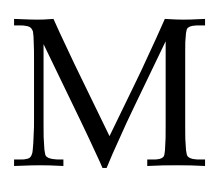

atematika selama ini dianggap sebagai dasar dari berbagai displin ilmu. Perkembangan ilmu pengetahuan dan teknologi dewasa ini tak lepas dari peran ilmu matematika. Matematika juga berperan dalam memajukan daya pikir manusia. Oleh karena itu, mempelajari matematika menjadi sesuatu yang penting. Hal ini terlihat dari dimasukkannya matematika sebagai salah satu mata pelajaran wajib di setiap jenjang pendidikan. UU Sisdiknas No. 20 Tahun 2003 Pasal 37 menegaskan bahwa matematika merupakan salah satu pelajaran wajib untuk siswa di sekolah dasar maupun menengah (Depdiknas, 2003).

Matematika pada dasarnya tidak bisa lepas dari aktivitas kehidupan manusia sehari-hari. Menurut Abdullah (2017), hal ini seharusnya membuat matematika mudah dipahami oleh siswa. Namun pada kenyataannya, matematika menjadi momok menakutkan bagi siswa. Banyak siswa yang merasa kesulitan mempelajari matematika. Hal ini disebabkan karena matematika yang diajarkan oleh guru di sekolah terkadang tidak sesuai dengan matematika yang berkembang dalam kehidupan sehari-hari. Ketidaksesuaian antara permasalahan matematika yang ada di sekolah dengan permasalahan matematika yang ada di kehidupan sehari-hari seringkali membuat siswa bingung dan kesulitan untuk mengaitkan konsep matematika yang diperoleh di sekolah dengan matematika di dunia nyata. Akibatnya, seringkali ditemukan adanya siswa yang mampu menyelesaikan permasalahan matematika di kehidupan sehari-hari, namun kesulitan menyelesaikan permasalahan matematika di kelas (D'Ambrosio, 1985). Oleh karena itu, pembelajaran matematika seharusnya mampu menjembatani antara matematika di kelas dan matematika dalam kehidupan sehari-hari. 
Kebudayaan lokal bisa dimanfaatkan sebagai sumber belajar yang kontekstual. Pembelajaran berbasis budaya bisa menjadi inovasi dalam pembelajaran matematika. Kajian tentang matematika berbasis budaya adalah etnomatematika. Etnomatematika didefinisikan sebagai antropologi budaya matematika yakni sebuah kajian tentang hubungan antara budaya dan matematika. Etnomatematika membedakan antara matematika di sekolah dengan matematika yang tertanam di dalam budaya yang terkadang jarang dijamah oleh sistem persekolahan (Turmudi, 2017).

Istilah etnomatematika pertama kali diperkenalkan oleh seorang matematikawan Brazil yaitu D'Ambrossio. Etnomatematika berasal dari kata ethnomathematics, yang terdiri dari tiga suku kata yaitu ethno, mathema, dan tics. Awalan ethno mengacu pada kelompok kebudayaan yang dapat dikenali, seperti perkumpulan suku di suatu negara dan kelas-kelas profesi di masyarakat, termasuk pula bahasa dan kebiasaan mereka sehari-hari. Mathema berarti menjelaskan, mengerti, dan mengelola hal-hal nyata secara spesifik dengan menghitung, mengukur, mengklasifkasi, mengurutkan, dan memodelkan suatu pola yang muncul pada suatu lingkungan; sedangkan tics berarti seni dalam teknik. Secara istilah, etnomatematika diartikan sebagai matematika yang dipraktikkan di dalam kelompok budaya seperti masyarakat nasional, suku, kelompok buruh, anak-anak dari kelompok usia tertentu dan kelas professional (D'Ambrosio, 1985).

Menurut Imswatama \& Setiadi (2017), penelitian di bidang etnomatematika telah menjangkau banyak sektor, seperti arsitektur, tenun, menjahit, ornamen, dan praktek spiritual dan keagamaan yang sering diselaraskan dengan pola yang terjadi di lingkungan. Salah satu bidang kajian matematika yang sering diteliti pada etnomatematika adalah geometri. Geometri merupakan salah satu cabang ilmu matematika yang mempelajari tentang titik, garis, bidang, bangun datar, dan bangun ruang. Geometri membahas masalah-masalah yang ada di kehidupan sehari-hari. Fenomena alam, bentuk-bentuk benda, serta kegiatan yang dilakukan sebagian besar merupakan hasil dari geometri (Isnawati \& Putra, 2017). Beberapa penelitian yang pernah dilakukan terkait geometri pada etnomatematika adalah penelitian tentang aplikasi bangun datar pada segiempat pada candi Muaro Jambi (Hardiarti, 2017). Penelitian lain adalah penelitian tentang penggunaan etnomatematika pada batik paoman dalam pembelajaran geometri bidang di sekolah dasar (Sudirman, Son, \& Rosyadi, 2018). Aplikasi geometri 
transformasi juga ditemukan melalui eksplorasi etnomatematika pada beberapa motif batik di Yogyakarta (Risdiyanti \& Prahmana, 2017).

Adapun aplikasi di bidang geometri lainnya dapat pula ditemui di dalam masyarakat Bugis. Bugis merupakan salah satu etnis terbesar di Indonesia, dimana kebudayaan lokal menjadi bagian penting yang tak terpisahkan dari kehidupan masyarakatnya. Masyarakat Bugis sangat menjunjung tinggi nilai-nilai budaya sehingga mereka selalu berusaha untuk melestarikan warisan budaya yang sudah ada sejak dahulu kala. Salah satu warisan budaya Bugis yang terkenal adalah makanan tradisional. Makanan tradisional Bugis selalu disajikan di setiap acara yang dilaksanakan di lingkungan masyarakat Bugis. Hal ini menjadikan makanan tradisional Bugis sangat familiar, termasuk di kalangan para siswa. Secara fisik, makanan tradisional Bugis memiliki bentuk-bentuk yang khas dan hampir tidak berubah sejak zaman dahulu. Jika diperhatikan lebih seksama, bentuk makanan ini mengandung konsep geometri. Dari bentuknya yang khas, maka penulis merasa perlu menggali dan mengeksplorasi lebih dalam lagi mengenai konsep-konsep geometri yang terdapat pada makanan tradisional Bugis agar dapat dijadikan sebagai salah satu sumber belajar matematika yang sangat dekat dengan kehidupan siswa. Berdasarkan latar belakang tersebut, maka sangat penting untuk diadakan penelitian tentang kaitan antara setiap bentuk dari jenis makanan tradisional Bugis dengan konsep-konsep matematika, khususnya geometri. Oleh karena itu, penulis tertarik untuk mengeksplorasi etnomatematika dari makanan tradisional Bugis.

\section{METODE PENELITIAN}

Penelitian ini merupakan penelitian kualitatif dengan pendekatan etnografi. Berdasarkan jenis dan pendekatan penelitian ini, maka instrumen yang digunakan adalah human instrument, dalam hal ini peneliti berhubungan langsung dengan penelitian dan berperan sebagai pengumpul data, serta tidak dapat digantikan perannya. Teknik pengumpulan data dilakukan melalui observasi, wawancara, dan dokumentasi.

Adapun prosedur penelitian yang dilakukan pada penelitian ini mengadopsi prosedur siklus penelitian etnografi oleh Spradley dalam Emzir (2017) yang mencakup enam langkah. Langkah pertama adalah pemilihan proyek etnografi. Siklus ini dimulai dengan memilih suatu proyek penelitan etnografi dengan mempertimbangkan ruang lingkup penelitian. Pada penelitian ini, penulis memilih melakukan penelitian di Kabupaten Sidrap 
yang merupakan salah satu daerah yang penduduknya mayoritas adalah suku Bugis. Penulis juga membatasi ruang lingkup penelitian yaitu hanya mengeksplorasi aktivitas etnomatematika dari makanan tradisional Bugis. Langkah kedua adalah pengajuan pertanyaan etnografi. Pada siklus ini, penulis mengajukan pertanyaan terhadap informan tentang hal-hal apa saja yang ingin penulis ketahui terkait dengan makanan tradisional Bugis. Informan yang diwawancarai adalah orang-orang yang sering terlibat langsung dalam proses pembuatan atau penjualan makanan tradisional Bugis. Langkah ketiga adalah pengumpulan data etnografi. Pada siklus ini, penulis mengumpulkan data melalui observasi lapangan di tempat-tempat pembuatan atau penjualan makanan tradisional Bugis. Data yang diperoleh berupa hasil pengamatan langsung dan deskripsi hasil pertanyaan dan jawaban dari informan. Langkah keempat adalah pembuatan rekaman etnografi. Pada tahap ini, penulis membuat rekaman etnografi berupa pengambilan catatan lapangan dan pengambilan foto. Foto-foto yang diambil pada tahap ini adalah foto makanan tradisional Bugis yang ditemukan di lapangan dan diduga memiliki keterkaitan dengan konsep-konsep geometri. Langkah kelima adalah analisis data etnografi. Pada tahap ini, penulis melakukan analisis terhadap data-data lapangan yang telah dikumpulkan. Analisis yang dilakukan meliputi analisis domain dan analisis taksonomi. Analisis domain dilakukan untuk memperoleh gambaran yang umum dan menyeluruh tentang objek yang diteliti, dalam hal ini adalah makanan tradisional Bugis. Selain itu, melalui analisis domain juga ditentukan kategori serta pengelompokan data yang diperoleh berdasarkan kategori-kategori tersebut. Selanjutnya, analisis taksonomi dilakukan dengan cara menjabarkan kategori-kategori tersebut dengan lebih rinci berdasarkan konsep-konsep matematika yang terdapat pada makanan tradisional Bugis. Langkah keenam adalah penulisan sebuah etnografi. Tahap terakhir dari prosedur penelitian ini adalah menyampaikan atau memaparkan hasil-hasil penelitian yang berupa hasil observasi lapangan, wawancara, dan dokumentasi yang isinya tentang deskripsi keterkaitan antara konsep geometri dengan makanan tradisional Bugis.

\section{HASIL PENELITIAN DAN PEMBAHASAN}

Berdasarkan hasil pengumpulan data penelitian, diperoleh 8 jenis makanan tradisional Bugis, yaitu barongko, onde-onde, doko-doko, paso, tumpi-tumpi, jompo-jompo, burasa', dan putu coppa. Dari hasil analisis terhadap bentuk-bentuk makanan tersebut, diketahui bahwa makanan 
tradisional Bugis tersebut memiliki bentuk-bentuk geometri berupa bangun datar dan bangun ruang. Konsep bangun datar pada makanan tradisional bugis adalah sebagai berikut.

\section{a. Tumpi-Tumpi}

Tumpi-Tumpi adalah salah satu makanan tradisional Bugis yang terbuat dari olahan ikan dan dicampur dengan kelapa parut.

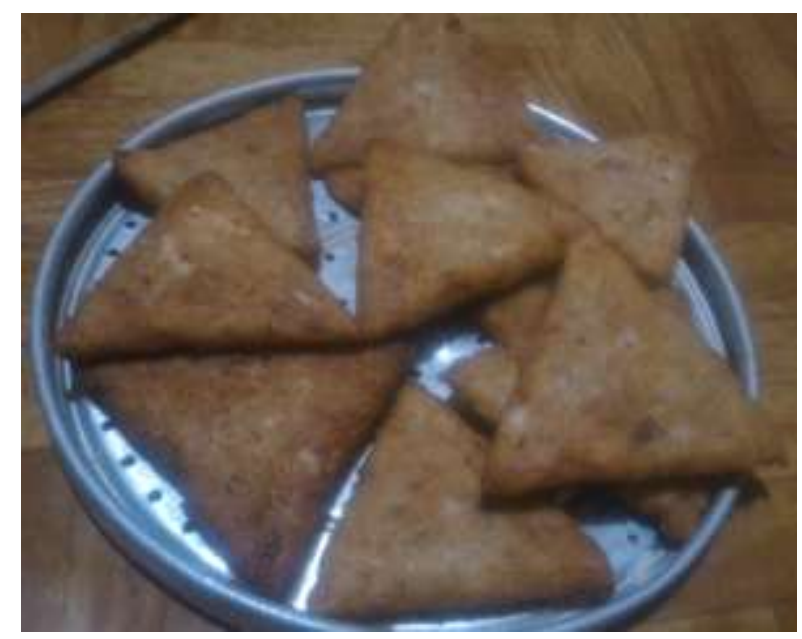

Gambar 1. Tumpi-Tumpi Bugis

Berikut adalah gambar pemodelan tumpi-tumpi secara geometri.
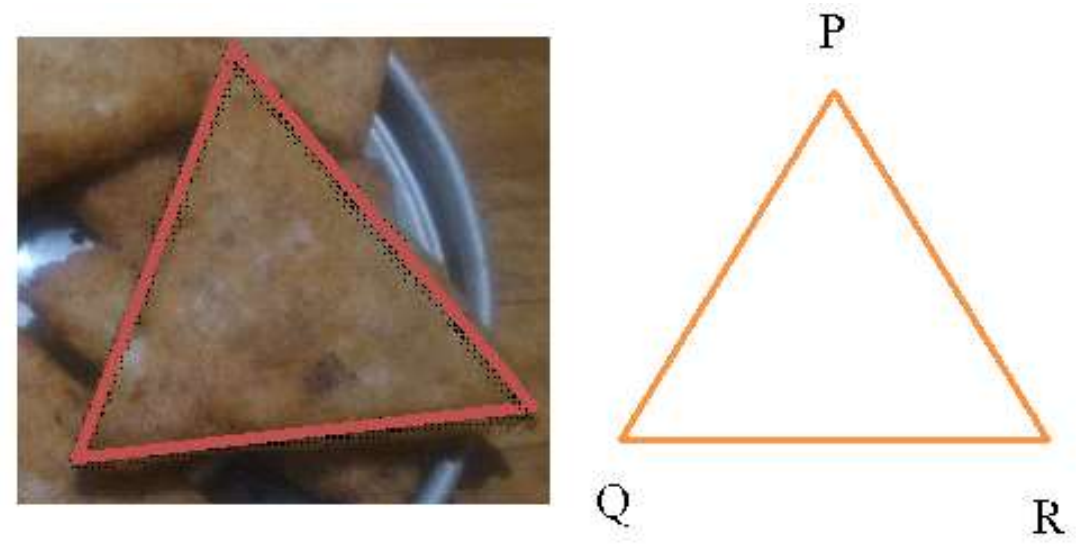

Gambar 2. Pemodelan Tumpi-Tumpi secara Geometri

Berdasarkan hasil analisis pada gambar 2, diketahui bahwa pada tumpi-tumpi terdapat konsep geometri yaitu segitiga sama sisi. Adapun sifatsifat segitiga sama sisi berdasarkan gambar 2 adalah sebagai berikut. 
Etnomatematika: Makanan Tradisional Bugis ....

Volume 7, No 2, December 2019 | 313 
1. Ketiga sisinya sama panjang

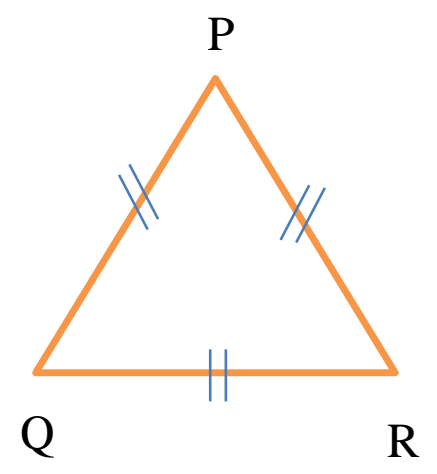

$$
P Q=P R=Q R
$$

2. Ketiga sudutnya sama besar

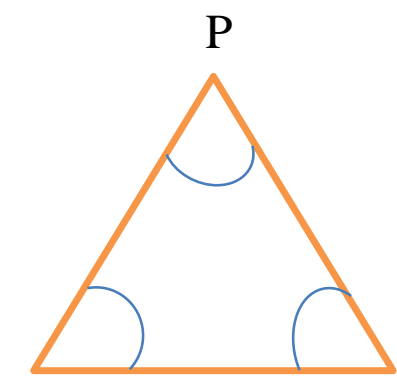

$$
\begin{aligned}
& \mathrm{Q} \\
& \angle P=\angle Q=\angle R=60^{\circ} \\
& \angle P+\angle Q+\angle R=180^{\circ}
\end{aligned}
$$

3. Mempunyai 3 simetri putar
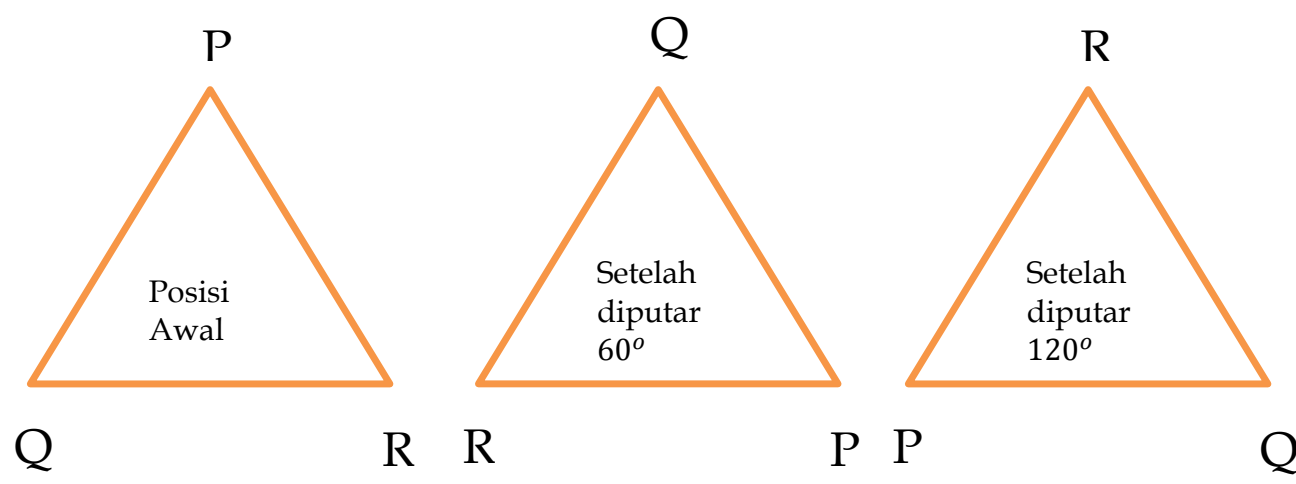

Q R R

P P

Q 
4. Mempunyai 3 simetri 1
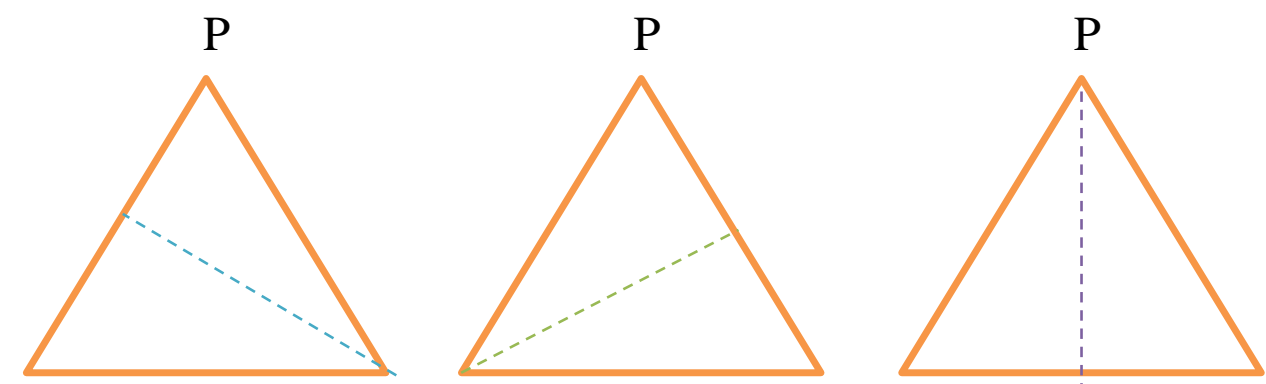

Q

R Q

R Q

$\mathrm{R}$

b. Jompo-Jompo

Jompo-Jompo merupakan salah satu makanan tradisional Bugis yang terbuat dari campuran tepung beras dan gula merah.

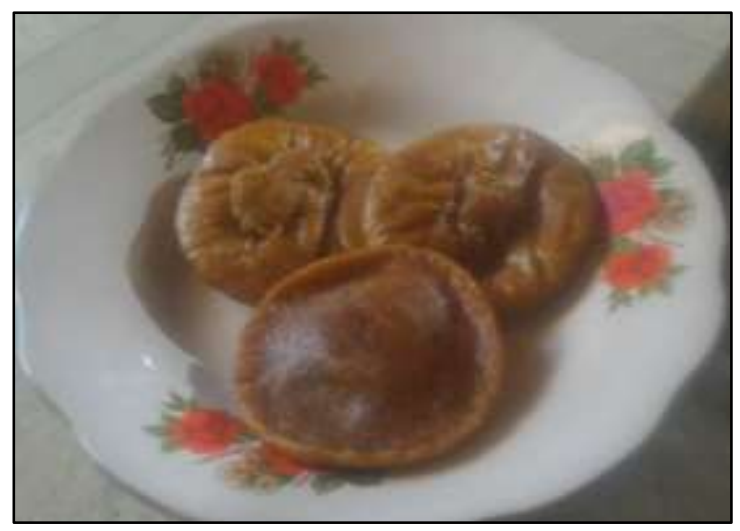

Gambar 3. Jompo-Jompo

Berikut adalah gambar pemodelan jompo-jompo secara geometri.
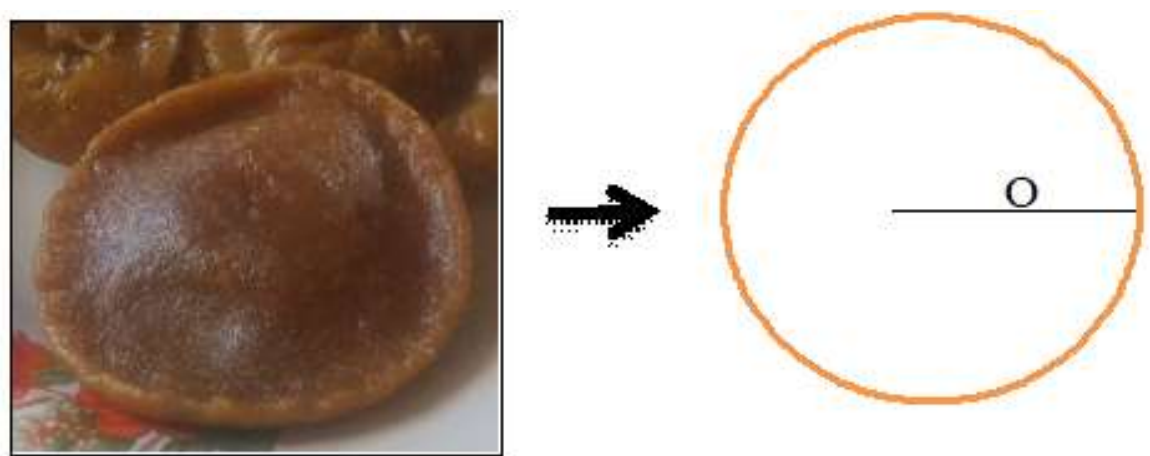

Gambar 4. Pemodelan Jompo-Jompo secara Geometri 
Berdasarkan hasil analisis pada gambar 4, diketahui bahwa pada jompo-jompo terdapat konsep geometri yaitu lingkaran. Adapun sifat-sifat lingkaran berdasarkan gambar 4 adalah sebagai berikut:

1. Hanya memiliki 1 sisi

2. Tidak memiliki titik sudut

3. Memiliki simetri lipat yang tidak terbatas jumlahnya

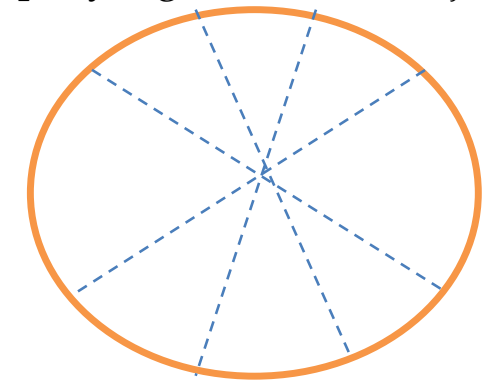

4. Memiliki simetri putar yang tidak terbatas jumlahnya



5. Jarak dari titik pusat ke titik manapun pada lingkaran selalu sama

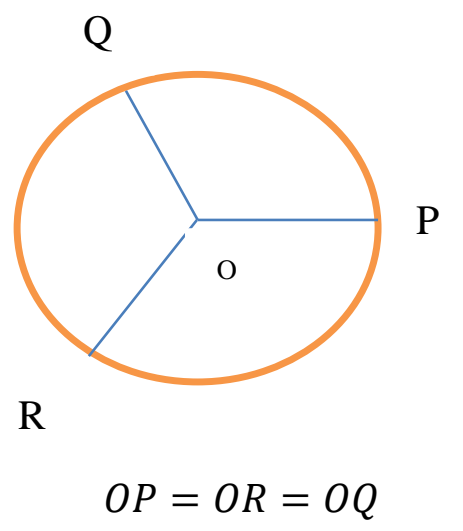

c. Burasa'

Burasa' adalah makanan khas Bugis yang terbuat dari beras yang diberi santan kemudian dibungkus dengan daun pisang. Makanan ini biasanya dijumpai saat hari raya Idul Fitri dan Idul Adha. Makanan ini juga seringkali jadi bekal bagi masyarakat Bugis yang akan bepergian. 


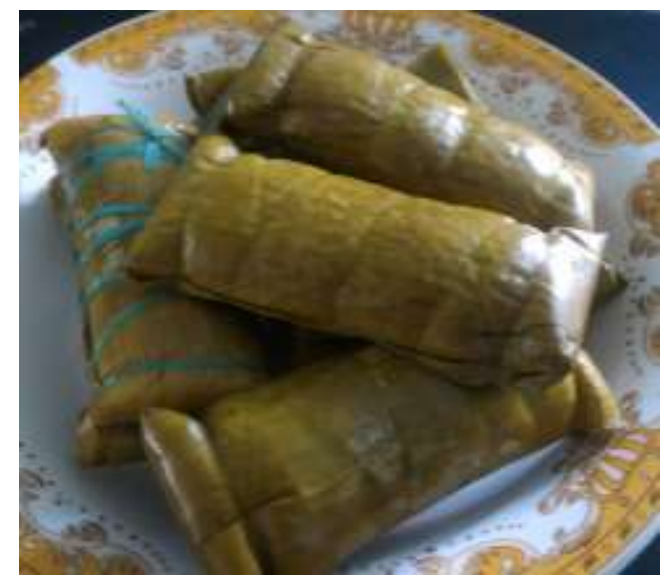

Gambar 5. Burasa'

Berikut adalah gambar pemodelan burasa' secara geometri.
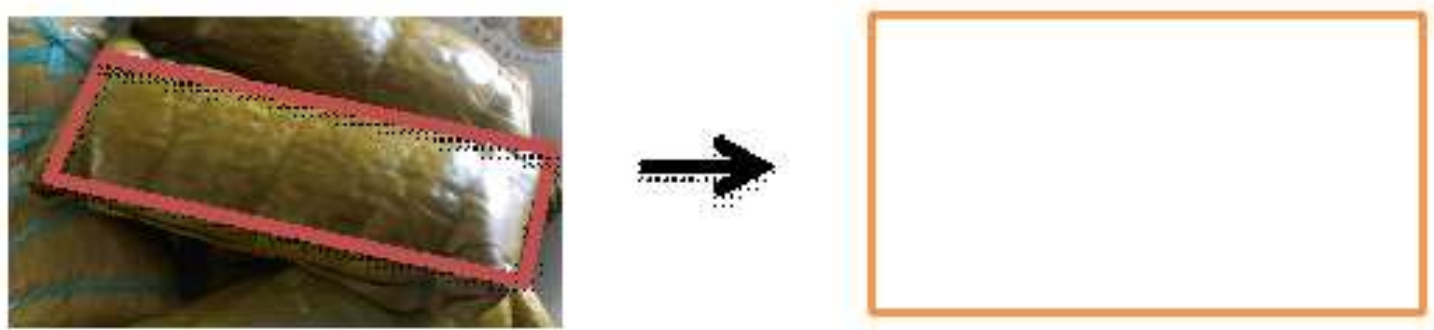

Gambar 6. Pemodelan Burasa' secara Geometri

Berdasarkan hasil analisis pada gambar 6, diketahui bahwa pada burasa' terdapat konsep geometri yaitu persegi panjang. Adapun sifat-sifat persegi panjang berdasarkan gambar 6 adalah sebagai berikut:

1. Sisi-sisi yang berhadapan sama panjang

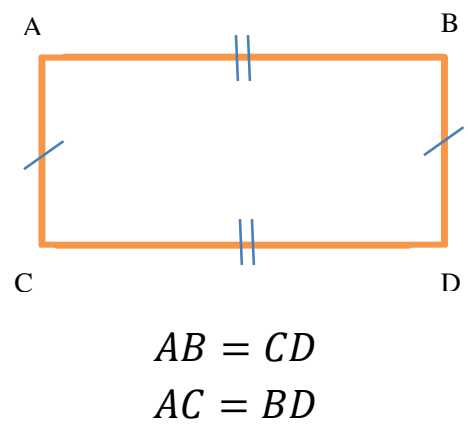


2. Keempat sudutnya siku-siku

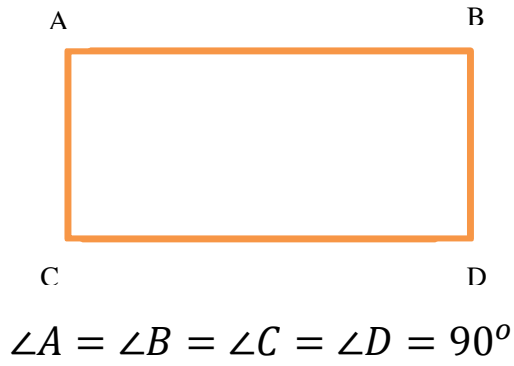

3. Kedua diagonalnya berpotongan dan membagi 2 sama panjang

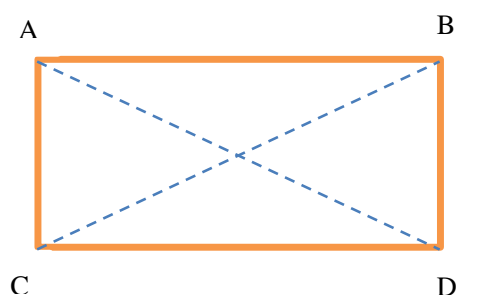

$$
A O=O D=C O=O B
$$

4. Memiliki 2 simetri lipat



5. Memiliki 2 simetri putar

A

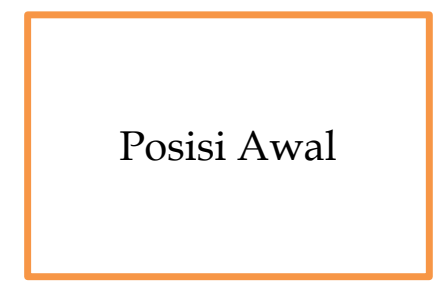

C
B

D

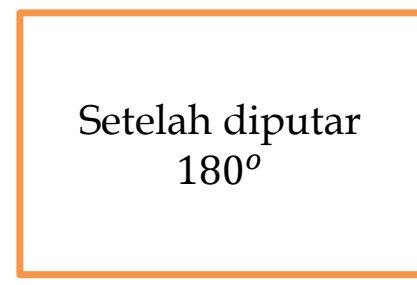

C A

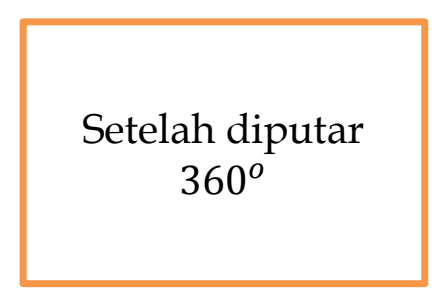

D B

A C

$\mathrm{D}$

Konsep Bangun Ruang pada Makanan Tradisional Bugis adalah sebagai berikut.

\section{a. Barongko}

Barongko adalah salah satu makanan khas Bugis yang cukup terkenal. Barongko terbuat dari campuran pisang yang dihaluskan dengan santan dan telur, lalu dibungkus dengan daun pisang. Kue ini sangat sering dihidangkan saat berlangsungnya acara adat Bugis seperti pernikahan. 


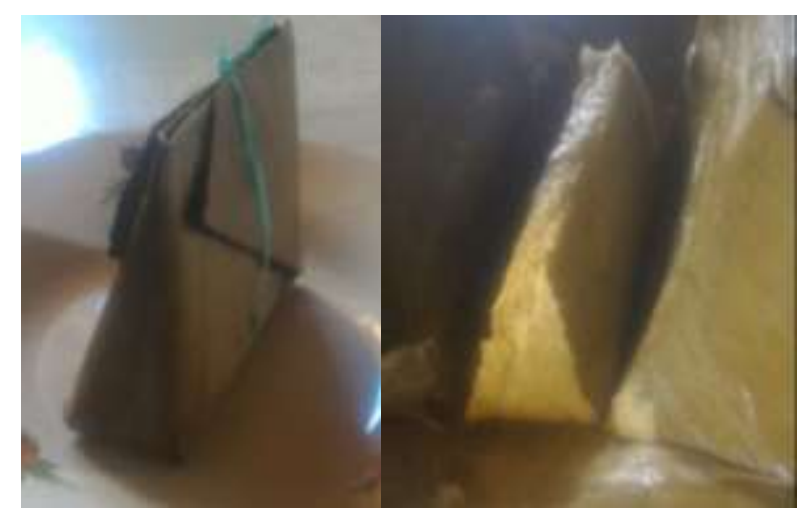

Gambar 7. Kue Barongko

Berikut adalah pemodelan barongko secara geometri.

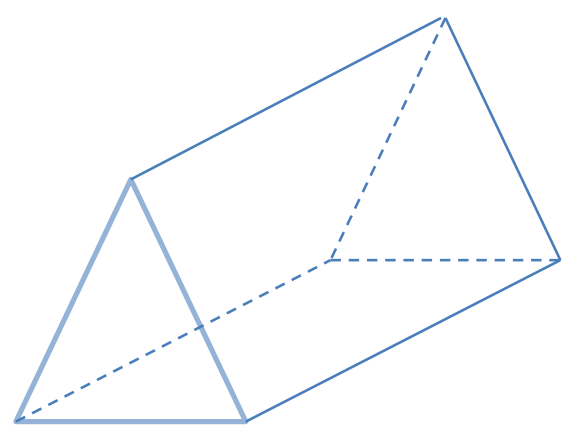

Gambar 8. Pemodelan Kue Barongko secara Geometri

Berdasarkan analisis dari gambar 8 di atas, diketahui bahwa kue barongko memiliki konsep geometri yaitu prisma segitiga. Adapun sifat-sifat dari prisma segitiga adalah sebagai berikut:

a. Memiliki 5 buah sisi, yang terdiri dari 2 buah segitiga kongruen dan 3 buah persegi panjang. Sisi segitiga kongruen adalah $\mathrm{ABE}$ dan CDF. Sisi persegi panjang adalah $\mathrm{ABCD}, \mathrm{BCEF}, \mathrm{ADEF}$.

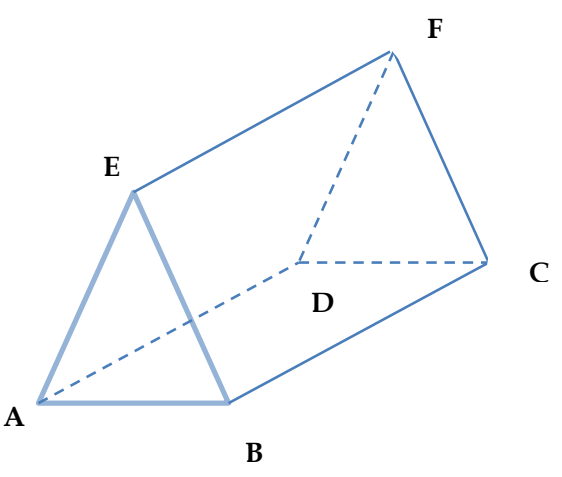


b. Memiliki 9 buah rusuk. Sembilan rusuk tersebut adalah AB, CD, AE, $\mathrm{CF}, \mathrm{BE}, \mathrm{DF}, \mathrm{BC}, \mathrm{EF}$, dan AD.

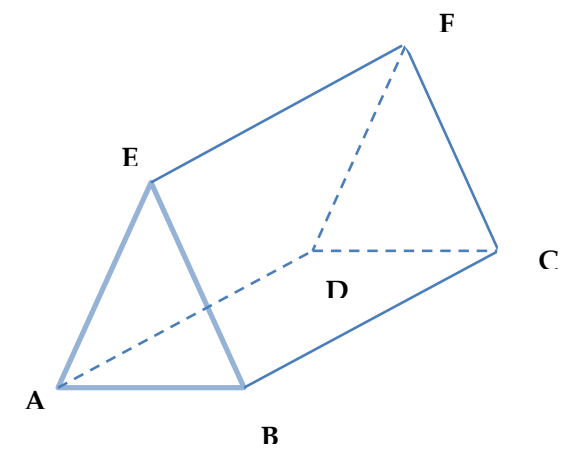

b. Onde-Onde

Onde-onde Bugis adalah salah satu makanan khas Sulawesi Selatan, khususnya di daerah Bugis. Onde-onde terbuat dari beras ketan yang di dalamnya diisi dengan gula merah dan di luarnya dibaluri dengan parutan kelapa.

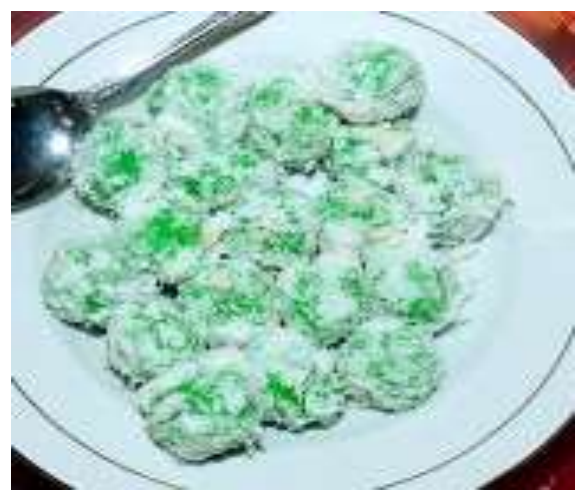

Gambar 9. Onde-Onde Bugis

(Sumber: kuebugisku.blogspot.com/2018/02/onde-onde.html)

Berikut adalah pemodelan onde-onde secara geometri.

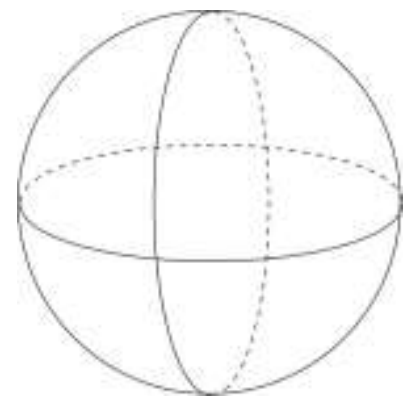

Gambar 10. Pemodelan Onde-Onde secara Geometri 
Berdasarkan analisis pada gambar 10, diketahui bahwa onde-onde memiliki bentuk geometri yaitu bola. Adapun sifat-sifat dari bola adalah sebagai berikut:

1. Mempunyai satu sisi

2. Tidak mempunyai titik sudut

3. Tidak mempunyai bidang datar

4. Hanya mempunyai satu bidang lengkung tertutup

\section{c. Doko-Doko}

Doko-Doko adalah makanan khas Bugis yang terbuat dari beras ketan dan di tengahnya diisi dengan isian kelapa yang dicampur dengan gula merah.

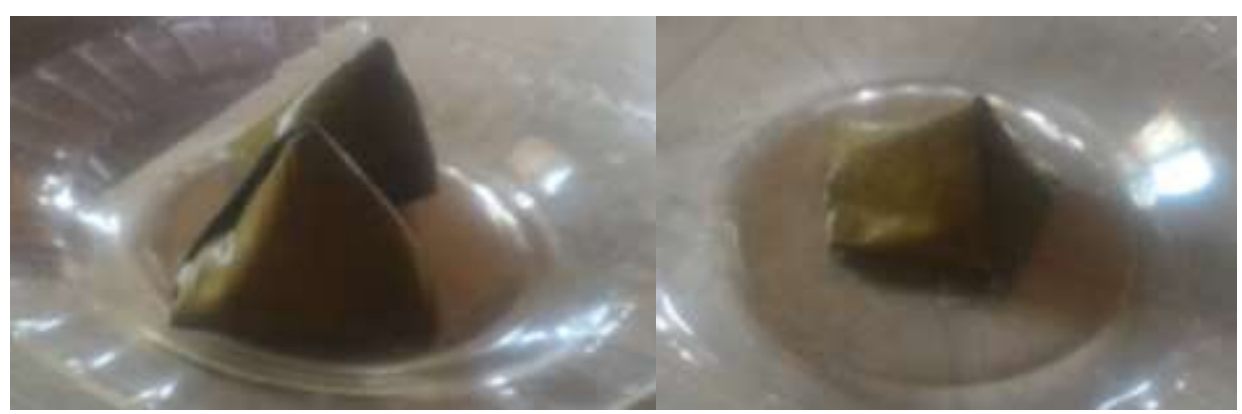

Gambar 11. Kue Doko-Doko

Berikut adalah pemodelan doko-doko secara geometri.

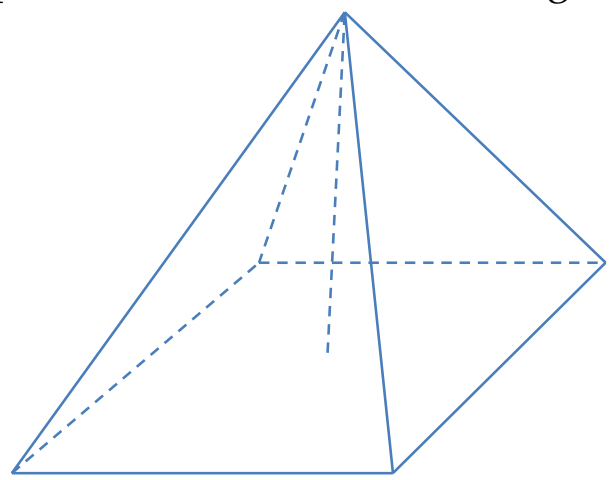

Gambar 12. Pemodelan Kue Doko-Doko secara Geometri

Berdasarkan analisis pada gambar 12, diketahui bahwa kue doko-doko memiliki bentuk geometri yaitu limas segiempat. Adapun sifat-sifat dari limas segiempat adalah sebagai berikut: 
1. Memiliki 5 sisi, di mana 4 sisi tegak berbentuk segitiga dan 1 sisi alas berbentuk segiempat. Sisi tegak adalah ABE, BCE, CDE, dan ADE. Sisi alas adalah ABCD.

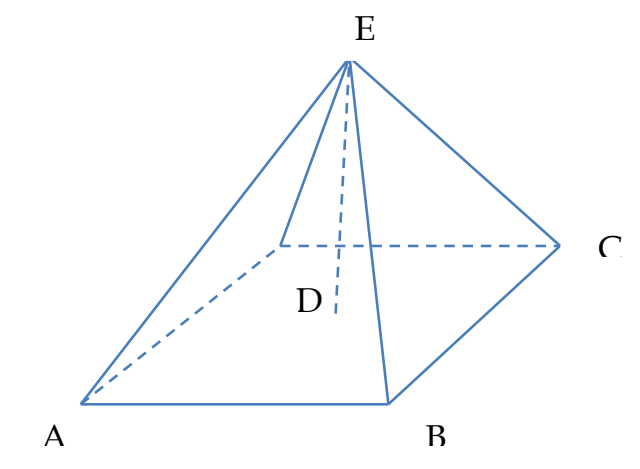

2. Memiliki 5 buah titik sudut Lima titik sudut tersebut adalah $\angle A, \angle B$, $\angle C, \angle D$, dan $\angle E$

d. Kue Paso

Paso adalah salah satu makanan tradisional bugis yang terbuat dari campuran dari tepung beras dan gula merah, serta dibungkus dengan pisang.

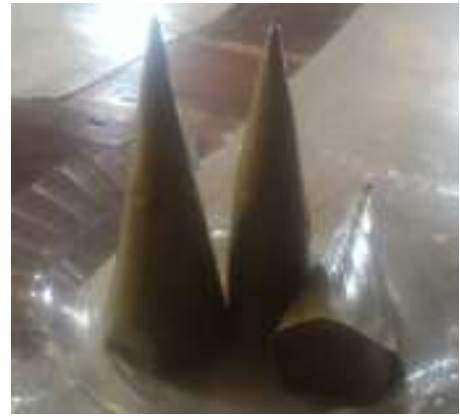

Gambar 13. Kue Paso

Berikut adalah pemodelan kue paso secara geometri.

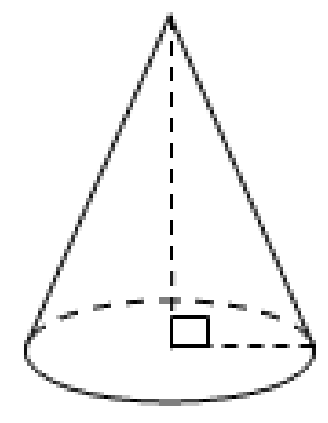

Gambar 14. Pemodelan Kue Paso secara Geometri 
Berdasarkan analisis dari gambar 14 di atas, diketahui bahwa pada kue paso terdapat konsep geometri yaitu bentuk kerucut. Adapun sifat-sifat dari kerucut adalah sebagai berikut:

1. Mempunyai 2 sisi, yang terdiri dari 1 sisi alas berbentuk lingkaran dan 1 sisi berbentuk bidang lengkung.

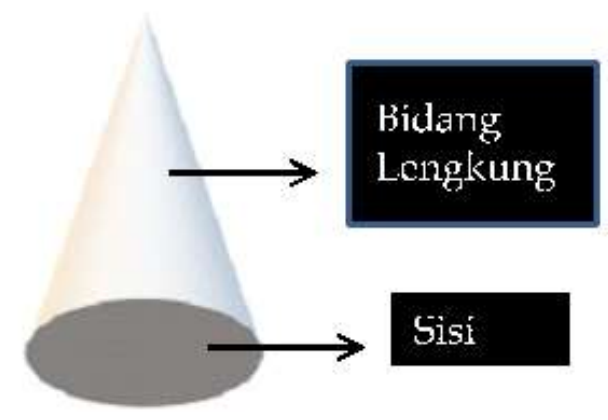

2. Mempunyai 1 rusuk lengkung

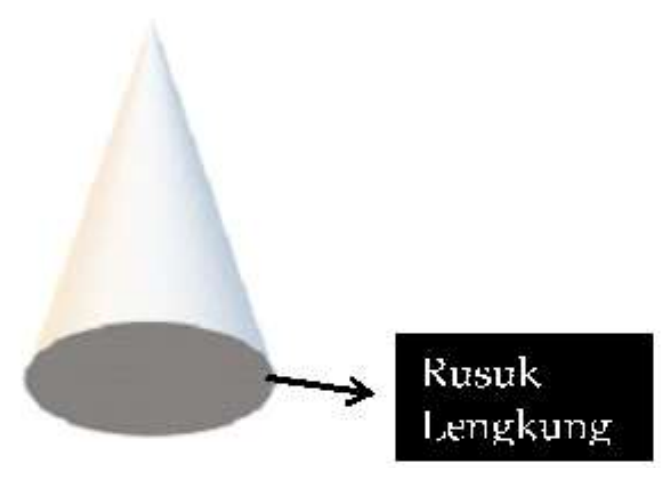

3. Tidak memiliki sudut dan memiliki 1 titik puncak

Tiitik P'uncik 


\section{e. Putu Coppa}

Putu Coppa adalah salah satu makanan khas Bugis yang terbuat dari beras ketan dan dibaluri dengan parutan kelapa. Biasanya dimakan bersama sambal khas Bugis. Makanan ini seringkali dijumpai di pagi hari sebagai pengganti nasi saat sarapan.

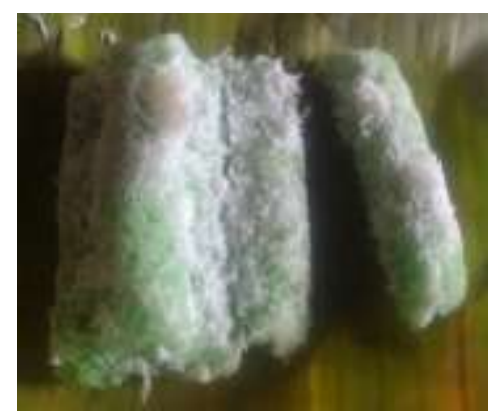

Gambar 15. Putu Coppa

Berikut adalah pemodelan putu coppa secara geometri.

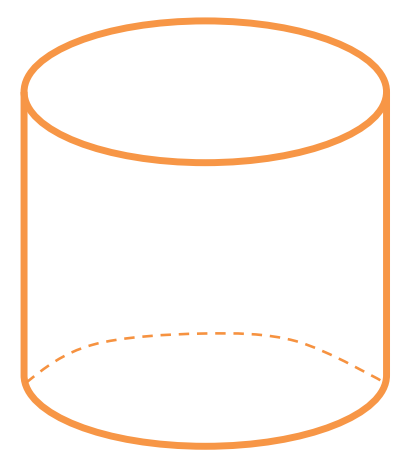

Gambar 16. Pemodelan Putu Coppa secara Geometri

Berdasarkan analisis dari gambar 16 di atas, diketahui bahwa pada putu coppa terdapat konsep geometri yaitu bentuk tabung. Adapun sifat-sifat dari tabung adalah sebagai berikut:

1. Bagian alas dan bagian bawahnya berbentuk lingkaran dan sama besar

2. Memiliki 3 sisi yaitu alas, atap, dan selimut

3. Tidak memiliki titik sudut

4. Memiliki 2 buah rusuk 


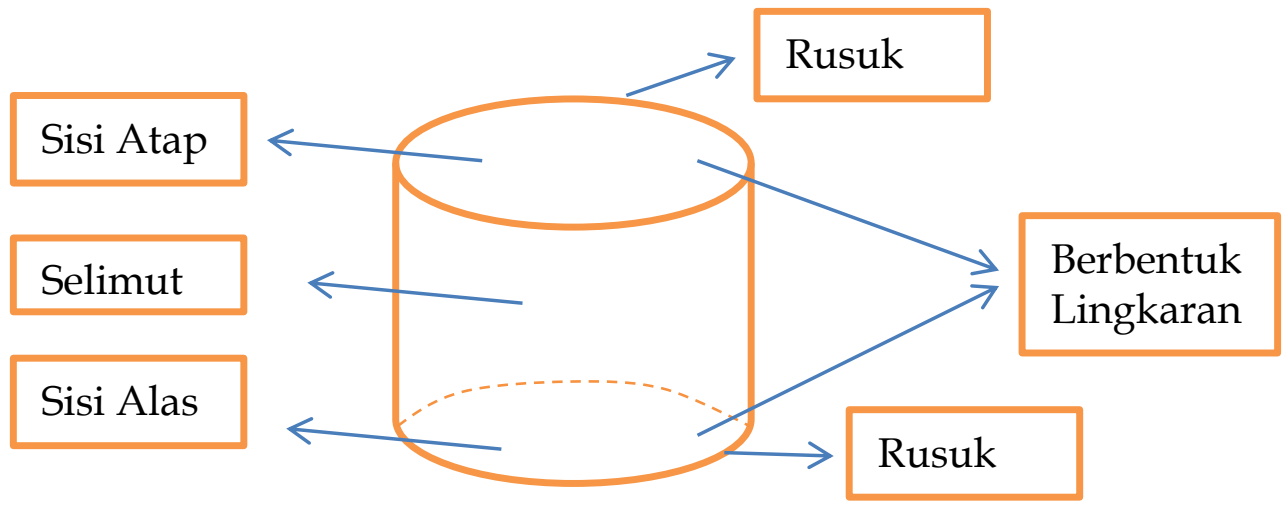

Berdasarkan hasil penelitian di atas, dapat diketahui bahwa makanan tradisional Bugis merupakan salah satu warisan budaya yang sangat dekat dengan kehidupan dan aktivitas siswa sehari-hari. Hampir semua siswa pernah memakan bahkan membuat makanan tersebut. Dengan demikian, makanan tradisional Bugis dapat dikembangkan menjadi salah satu sumber belajar matematika siswa yang lebih konkret. Siswa dapat diminta untuk mengamati makanan tradisional tersebut, kemudian diminta untuk mengidentifikasi konsep-konsep geometri yang ada di dalamnya.

Pada pembelajaran di sekolah dasar, guru dapat meminta siswa untuk membawa salah satu jenis makanan tradisional Bugis. Setelah itu, siswa dapat meminta untuk mengamati serta mengidentifikasi bentuk serta karakteristik dari makanan tradisional tersebut. Dengan demikian, siswa dapat belajar geometri secara kontekstual. Pada pembelajaran di sekolah menengah, guru bisa mengembangkan materi pembelajaran pada pengenalan keliling dan luas bangun datar dan bangun ruang. Guru dapat mengajukan pertanyaan yang berkaitan dengan makanan tradisional Bugis untuk menstimulasi siswa berpikir kreatif. Contoh pertanyaannya sebagai berikut.

1. Pada hari Sabtu, Ibu berencana membuat kue barongko. Pertama-tama, Ibu membuat adonan barongko yang terbuat dari pisang yang dihaluskan, telur, gula, dan santan. Setelah itu, Ibu mengambil daun pisang dan membuat pembungkus barongko dengan luas alas $25 \mathrm{~cm}^{2}$ dan tinggi $15 \mathrm{~cm}$. Agar adonan tidak tumpah, maka pembungkus barongko hanya bisa diisi 1/2 nya. Berapa banyak adonan yang bisa Ibu masukkan ke dalam sebuah pembungkus barongko?

2. Saat libur sekolah, Indah dan teman-temannya berencana untuk berwisata di pantai. Sebelum berangkat, ia ingin membuat burasa sebagai bekal selama di perjalanan. Untuk membuat satu bungkus burasa, dibutuhkan daun pisang dengan ukuran $10 \mathrm{~cm} \times 12 \mathrm{~cm}$. Jika dalam satu ikat terdiri dari 
3 buah burasa, berapa ikatkah yang dapat Indah buat dari 2 buah pelepah pisang yang berukuran $12 \mathrm{~cm} \times 100 \mathrm{~cm}$ ?

3. Dalam sebuah pesta adat, seorang juru masak diminta untuk membuat makanan tradisional berbentuk segitiga sama sisi yaitu tumpi-tumpi. Ukuran tumpi-tumpi tersebut harus sama besar. Jika disyaratkan bahwa keliling dari sebuah tumpi-tumpi haruslah $18 \mathrm{~cm}$, maka berapakah panjang sisi tumpi-tumpi yang harus dibuat oleh sang juru masak?

4. Kue kesukaan Ana adalah kue paso. Suatu hari, kakak Ana berencana membuat kue paso untuk adiknya. Pertama-tama, ia membuat adonan yang terdiri dari campuran tepung, gula aren, air, dan santan. Kemudian ia membuat cetakan dari daun pisang yang dibentuk kerucut menyerupai topi ulang tahun. Cetakan tersebut berdiameter $7 \mathrm{~cm}$ dengan tinggi $9 \mathrm{~cm}$. Agar adonan tidak tumpah, maka kakak Ana hanya boleh menuang adonan hingga $1 \mathrm{~cm}$ di bawah batas cetakan. Berapakah banyaknya adonan yang bisa dituang oleh kakak Ana?

5. Di sebuah kelas kursus memasak, peserta diminta untuk membuat kue onde-onde dengan ketentuan bahwa luas permukaannya adalah $16 \pi$. Berapakah diameter dari kue onde-onde yang harus dibuat oleh para peserta?

6. Diketahui volume dari suatu adonan jompo-jompo adalah $20.953 \mathrm{~cm}^{3}$. Untuk menuangkan adonan ke wajan, digunakan sendok sayur berbentuk setengah lingkaran dengan jari-jari $10 \mathrm{~cm}$. Jika dibutuhkan waktu 10 menit untuk memasak 1 jompo-jompo di wajan, berapa lama waktu yang digunakan untuk memasak habis adonan tersebut? (catatan: 1 kali menuangkan adonan menghasilkan 1 jompo-jompo).

Dengan menggunakan makanan tradisional Bugis sebagai sumber belajar, siswa diharapkan dapat termotivasi dalam pembelajaran matematika dan lebih mudah memahami konsep-konsep matematika terutama geometri.

\section{SIMPULAN}

Berdasarkan hasil penelitian, dapat disimpulkan bahwa terdapat unsur etnomatematika pada makanan tradisional Bugis yaitu konsep geometri yang terdiri dari bangun datar dan bangun ruang. Terdapat delapan jenis makanan tradisional Bugis yang mengandung konsep geometri yaitu tumpi-tumpi, jompo-jompo, burasa, barongko, onde-onde, doko-doko, paso, dan putu coppa. Konsep bangun datar yang ditemukan adalah segitiga (tumpi-tumpi), lingkaran (jompo-jompo), dan persegi panjang (burasa'), sementara konsep 
bangun ruang yang ditemukan diantaranya adalah prisma (barongko), bola (onde-onde), limas (doko-doko), kerucut (paso), dan tabung (putu coppa). Guru dapat memanfaatkan bentuk-bentuk makanan tradisional Bugis tersebut sebagai sumber belajar matematika yang lebih konkret dan inovatif, serta dapat digunakan untuk meningkatkan proses berpikir kritis siswa. Dengan demikian, pembelajaran matematika akan menjadi lebih bermakna karena sumber belajar berasal dari lingkungan sekitar siswa.

\section{DAFTAR PUSTAKA}

Abdullah, A. S. (2017). Ethnomathematics in perspective of sundanese. Journal on Mathematics Education, 8(1), 1-16. https:/ / doi.org/doi.org/10.22342/ jme.8.1.3877.1-16.

D'Ambrosio, U. (1985). Ethnomathematics and its place in the history and pedagogy of mathematics. For the Learning of Mathematics, 5(1), 44-48. Retrieved from https://www.usd.ac.id/fakultas/pendidikan/s2_pen_ matematika/f113/ An article by Ubiratan D' Ambrosio.pdf.

Depdiknas. (2003). Undang-undang republik indonesia nomor 20 tahun 2003 tentang sistem pendidikan nasional. Jakarta: Depdiknas.

Emzir. (2017). Metodologi penelitian pendidikan kuantitatif $\mathcal{E}$ kualitatif. Jakarta: PT. RajaGrafindo Persada.

Hardiarti, S. (2017). Etnomatematika: Aplikasi bangun datar. Aksioma, 8(2), 99110. Retrieved from https://media.neliti.com/media/publications/217 393-none.pdf.

Imswatama, A., \& Setiadi, D. (2017). The etnomathematics of calculating an auspicious day process in the javanese society as mathematics learning. In Proceeding of The 4th International Symposium on Mathematics Education and Innovation (ISMEI) (pp. 105-111). Retrieved from http://eprints.ummi.ac.id/95/1/The Etnomathematics of Calculating An Auspicious Day Process In The Javanese Society as Mathematics Learning.pdf.

Isnawati, L. Z., \& Putra, F. G. (2017). Analisis unsur matematika pada motif sulam usus. Jurnal Matematika Dan Pendidikan Matematika, 1(2), 173-192. https:// doi.org/doi.org/10.25217/numerical.v1i2.130.

Risdiyanti, I., \& Prahmana, R. C. I. (2017). Ethnomathematics: Exploration in Javanese culture. In Journal of Physics: Conference Series (pp. 1-6). Retrieved from https://iopscience.iop.org/article/10.1088/17426596/943/1/012032.

Sudirman, Son, A. L., \& Rosyadi. (2018). Penggunaan etnomatematika pada batik paoman dalam pembelajaran. Indomath: Indomanesian Mathematics Education, 1(1), 27-34. https://doi.org/dx.doi.org/10.30738/indomath. v1i1.2093. 
Turmudi. (2017). Ethnomathematics: Apa mengapa dan bagaimana implementasi dalam pembelajaran matematika di kelas. In Seminar Nasional Matematika dan Pendidikan Matematika (2nd SENATIK) (pp. 1-9). Retrieved from http://prosiding.upgris.ac.id/index.php/sen_2017/sen _2017/paper/view/1625/1580. 